\title{
Power Flow Control and N-1 Contingency Analysis with DSRs in Unbalanced Transmission Networks
}

\author{
Shaimaa Omran ${ }^{\mathrm{a},{ }^{*}}$, Robert Broadwater ${ }^{\mathrm{a}}$, Joshua Hambrick ${ }^{\mathrm{b}}$, Murat Dilek ${ }^{\mathrm{b}}$, Chifong Thomas ${ }^{\mathrm{c}}$, and \\ Frank Kreikebaum $^{\mathrm{c}}$ \\ ${ }^{\text {a }}$ ECE department, Virginia Tech, Blacksburg, VA 24061 USA \\ ${ }^{\mathrm{b}}$ Electrical Distribution Design, Blacksburg, VA 24061 USA \\ ${ }^{\text {c }}$ Smart Wire Grid, Oakland, CA, 94612 USA
}

Abstract: The need for modern electricity infrastructures and more capable grid components brings attention to Distributed Series Reactor (DSR) technology because of its control capabilities. DSRs are a new smart grid technology that can be applied to control flows in transmission or distribution systems. Design of DSRs to control power flow over transmission lines to alleviate overloads due to load growth under single line contingencies is investigated in this paper. $\mathrm{N}-1$ contingency analysis is performed to assure secure operation of the grid while controlling the active power flow. The IEEE 39 bus standard model is modified to a 3-phase, unbalanced transmission model with $345 \mathrm{kV}$ lines that accounts for tower geometry. The design of DSRs to control power flow under N-1 line contingency is performed using this modified 3-phase, unbalanced model. DSR design to control the power flow of a real power system over tie lines connecting different power pool areas and to control the power flow over transmission lines within the area itself is investigated. The economics of DSRs are then evaluated by comparing the DSR design with a design that uses new line construction.

Keywords: Distributed Series Reactor(DSR) Design, Electric Power Transfer, Load Growth, N-1 Contingency Analysis, Power Flow Control, Unbalanced Transmission Systems.

\section{Introduction}

The US grid is frequently described as aging. Today's grid meets today's requirements, but new and different demands are driving the expansion and adaptation of the transmission grid and the evolution of its supporting institutions. Utilities in North America and all over the world are trying to incorporate new technological innovations to expand the transmission capacity using current assets and facilities [1]. Ways to expand transmission system capacity with no new transmission

\footnotetext{
${ }^{*}$ Corresponding author email: shmomran@vt.edu (S Omran)

Email addresses: dew@vt.edu (R Broadwater), josh-hambrick@edd-us.com (J Hambrick), murat-dilek@edd-us.com (M Dilek), Chifong.Thomas@smartwiregrid.com (C Thomas), Frank.Kreikebaum@smartwiregrid.com (F Kreikebaum)
} 
construction have been presented in the literature [2], [3]. Controlling power flow over lines to enhance system capacity has been also addressed in the literature [4],[5],[6].

In this paper we continue the line of research initiated in [7]-[11], devoted to the investigation of Distributed Series Reactor (DSR) deployment for controlling flows over transmission lines. DSRs can be used to control power flow over lines to enhance system capacity, alleviate overloads, and improve the reliability. DSRs are used to balance flows in the phases of an unbalanced line, and to control the distribution of flow in parallel paths.

Adjusting the impedance and admittance of transmission lines is one method of power flow control. A number of FACTS devices, such as STATCOM, SVC, SSSC and UPFC, have emerged. These technologies are based on power electronics. They can be inserted in series or shunt, or a combination of the two, to perform control functions, including voltage regulation, system damping and power flow control. Historically, challenges that have impeded the wide scale deployment of FACTS devices are high cost and maintenance complexity [7]. DSRs are relatively simple devices and hold the promise of high reliability and low maintenance.

Contingencies may be caused by widespread severe weather, a desire to expand supply capacity and meet short lead times to encourage new industries, retirement of coal plants, or a need for line uprating due to outages, may challenge the ability of a grid to meet criteria for delivering power during certain windows of time [8]. Much work has been done in the contingency analysis area [12]-[17]. Recent research addressed how different FACTS devices operate under contingency conditions to enhance the transmission system voltage stability, steady state security limit and to alleviate thermal overloads [18]-[24].

As the security and reliability of the grid are vital concerns, system operators commonly perform N-1 contingency analyses. Disturbances, like line outages, if not healed in a timely manner, can result in cascading outages leading to wide-spread blackouts. In this paper DSR design for N-1 contingencies with load growth in an unbalanced 3- phase transmission model is addressed. 
The IEEE 39 bus test system is modified to a 3-phase, $345 \mathrm{kV}$, unbalanced model, and is used to study the deployment of DSRs for controlling power flow to alleviate overloads due to load growth under single contingencies.

The contribution of this work is the design of the DSR controller for an unbalanced, 3-phase transmission system and the investigation of the operation of the controller under N-1 contingency conditions. No previous papers in the literature studied the application of DSRs in unbalanced 3phase transmission systems, and many of the transmission lines in the US are unbalanced.This paper will also present an economic case study to evaluate the value of DSRs in comparison to construction of new transmission lines.

\section{DSR Technology And Design Strategy For Handling N-1 Contingencies With Load Growth}

DSR technology is based on modifying the series reactance of a transmission line. DSR modules are mounted on the transmission conductor and may be activated to increase the series reactance of the line. When alternate flow paths exist in the transmission system the increase in series reactance of the line will cause flow to shift to the alternate paths.

The DSR addition affects the self-impedance of the line impedance matrix $\mathrm{Z}$ where $\mathrm{Z}_{\mathrm{ii}}=$ self-impedance of phase $\mathrm{i}$, and $\mathrm{i}=\mathrm{A}, \mathrm{B}, \mathrm{C}$.

$\mathrm{Z}_{\mathrm{ij}}=$ mutual impedance between phases $\mathrm{i}$ and $\mathrm{j}$, and $\mathrm{i}, \mathrm{j}=\mathrm{A}, \mathrm{B}, \mathrm{C}$.

In the work here, the DSR adds reactance to the self-impedance of the line model. The value of the reactance added depends on the number of DSR modules activated and the selected reactance for each DSR module [7],[8]. In this study the DSR modules inject 50 $\mu \mathrm{H} /$ module $(0.01885$ ohms). The objective of the DSR design here is to handle all N-1 contingencies that may occur in the system with load growth. This means that the DSRs are deployed to ensure that all lines operate within thermal ratings with the increased load, even with any single line failure of the 35 lines in the model. 
The DSR design and placement algorithm deploys DSRs on the transmission lines that provide the largest MW flow decrease in the overloaded lines. This is accomplished by calculating for a given line the change in MW in the overloaded lines for DSR addition to the given line. Thus, a line receiving DSRs may not be overloaded. This sensitivity is dependent on the utilization factor of the line. Accordingly, a set of lines are selected for DSR placement. DSR modules are placed iteratively with a certain step size that is chosen as the number of modules per phase. The step size (i.e., the number of DSRs added per iteration, is an input to the program). In the work here 25 DSRs per step are used. Using the chosen step size and sensitivity results derived from a three-phase, unbalanced power flow, the DSRs are deployed iteratively until the stopping criterion is fulfilled [25]. The stopping criterion adopted is to have no overloads in the system.Fig. 1 is a flowchart that depicts the design algorithm for DSR deployment for load growth with N-1 contingencies.

The following describes how lines are selected for DSR additions.

Let $\mathrm{O}_{\mathrm{Bij}}=$ overload of line $\mathrm{i}$ before DSRs are added to line $\mathrm{j}$, in MW

$\mathrm{O}_{\mathrm{Aij}}=$ overload of line $\mathrm{i}$ after DSRs are added to line $\mathrm{j}$, in MW

Define $\quad \Delta \mathrm{OL}_{\mathrm{j}}=\Sigma \mathrm{O}_{\mathrm{Bij}}-\mathrm{O}_{\mathrm{Aij}}$

Thus $\Delta \mathrm{OL}_{\mathrm{j}}$ represents the total decrease in overloads considering all overloaded lines in the system where DSRs are added to line $\mathrm{j}$. The line ' $\mathrm{s}$ ' to add DSRs to is then selected by

$$
\Delta \mathrm{OL}_{\mathrm{s}}=\max \text { over } \mathrm{j}\left\{\Delta \mathrm{OL}_{\mathrm{j}}\right\}
$$

Thus, the line is selected where $\Delta \mathrm{OL}_{\mathrm{j}} / \mathrm{Dsr}$ is the greatest, where Dsr is the number of DSRs added at each step. The algorithm used is based upon Discrete Ascent Optimal Programming, which is a greedy algorithm [26].The Discrete Ascent Optimal Programming algorithm uses the sensitivity of flow in one line due to the impedance change in another line. Since the sensitivities are calculated for each phase, the unbalanced effects are included. However, a symmetrical placement of DSRs is used in this work. The DSR design is done assuming the deployment of the same number of DSRs per phase. 
In the work here the load is uniformly grown in discrete increments, where the N-1 contingency criterion is considered for each load growth increment. When an overload is observed the DSR placement algorithm presented in Fig.1 is used to try and find a DSR design that can be used to

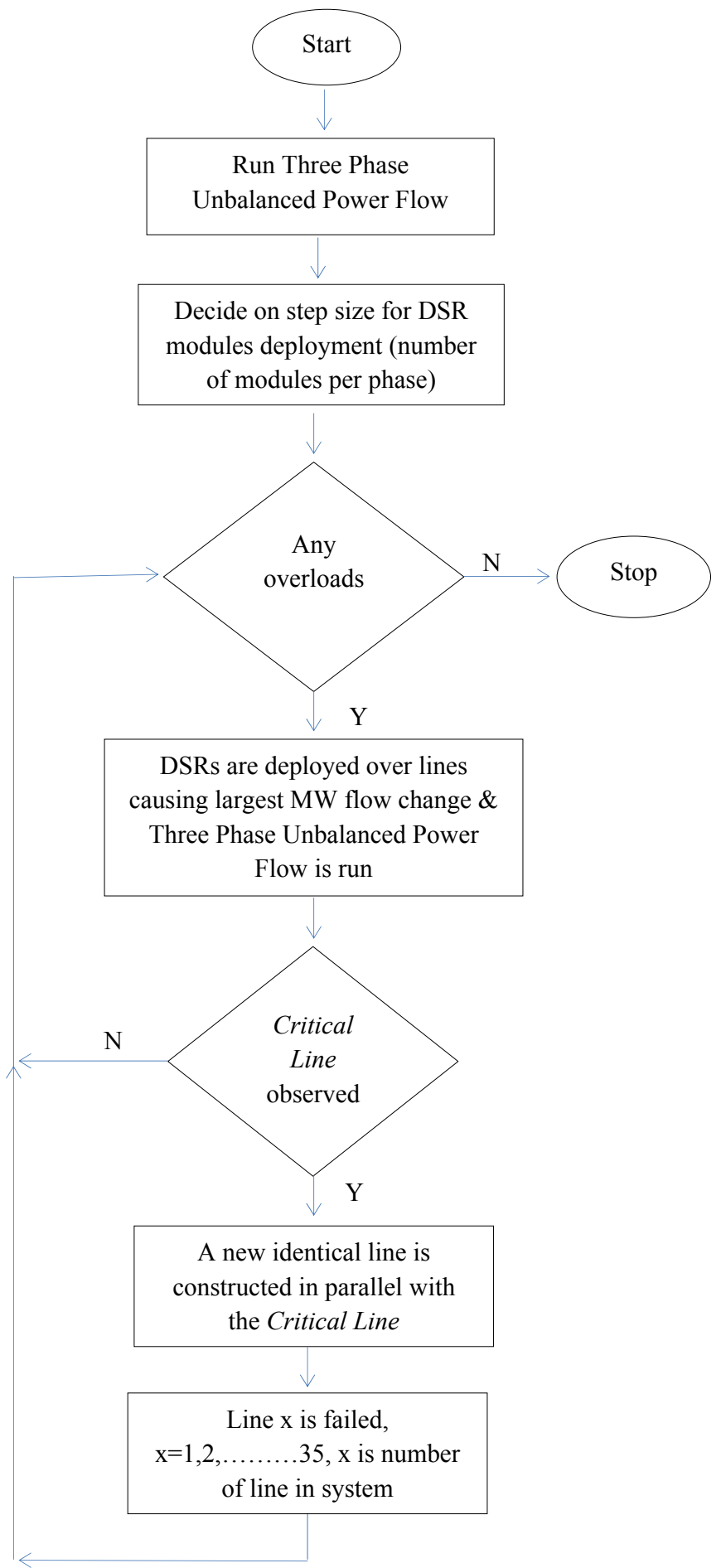

Fig.1 Flowchart of DSR placement algorithm for load growth and N-1 contingencies 
alleviate the overload. If DSRs are not able to handle overloads when a certain line is failed, a $345 \mathrm{kV}$ line will be added in parallel with the failed line that has identical characteristics to the original $345 \mathrm{kV}$ lines [27]. A line whose failure results in the DSR design being ineffective in handling the overloads is defined as a Critical Line. That is to say, when a line is failed and overloads that result cannot be alleviated by DSR placement, then the failed line is called a Critical Line. To handle the overload created by the failure of a Critical Line, a new identical line is constructed in parallel with the Critical Line. Once the new line is constructed, it remains in the system and is used in all future designs. The Critical Lines identify weak points in the system. Each time the load is grown or the system is strengthened, a new design is initiated. In other words, after each load increment or new line construction, a total new DSR design is applied.

\section{IEEE 39 bus Three-phase System Characteristics And Description}

The IEEE 39 bus test system is modified to a 3-phase model and is used to study the deployment of DSRs for controlling power flow to alleviate overloads due to load growth with N-1 line contingency. To address the consideration of generation in the design study, the ten generators in the IEEE standard model are replaced with three-phase equivalent voltage sources, where the solution of the model with the equivalent voltage sources is the same as the solution with the original power generators of the standard IEEE 39 bus model[25]. The voltage magnitude and angle of the sources are maintained constant as the load is grown. The system under study has ten voltage sources, 19 loads, and 35 lines. The transmission lines in the IEEE 39 bus standard transmission system are converted to $345 \mathrm{kV}$ lines.

The unbalanced impedance model of the lines is used, where the line impedance matrixhas selfimpedances that are unequal and symmetrical but unequal off diagonal elements. The same is true for the shunt admittance matrix of the unbalanced model.

For the unbalanced impedance model, the impedance matrix for the transmission lines is given by 


$$
\mathrm{Z}_{\text {line }}=\left[\begin{array}{lll}
0.18+j 1.27 & 0.13+j 0.53 & 0.14+j 0.44 \\
0.13+j 0.53 & 0.19+j 1.26 & 0.14+j 0.52 \\
0.14+j 0.44 & 0.14+j 0.52 & 0.21+j 1.24
\end{array}\right] \Omega / \text { mile (3) }
$$

and the shunt admittance matrix is

$$
\mathrm{Y}_{\text {line }}=\left[\begin{array}{ccc}
j 4.938 & -j 0.930 & -j 0.405 \\
-j 0.930 & j 4.977 & -j 0.941 \\
-j 0.405 & -j 0.941 & j 4.934
\end{array}\right] \mu \mathrm{S} / \text { mile (4) }
$$

\section{SimulationResults of DSR Design for N-1 Contingency with Load Growth}

The N-1 contingency analysis is first performed for the base case at $100 \%$ load, then the load is increased and the N-1 contingency analysis is performed for each increased load level. For each load level a totally new DSR design is initiated. We are assuming that the projected load growth for the next 40 years is $1 \%$ per year. We want to evaluate DSRs that will be needed for the projected load growth to handle overloads during contingencies. Results and findings for the critical lines, and the total number of DSRs deployed for each design are presented in Table 1. The DSR modules deployed over each line for each load level is presented in Table 2. As the addition of DSRs affects the series line impedance value, the percentage change in impedance was tracked and the maximum percentage change in impedance was calculated for lines that have DSRs deployed over them. These are recorded in Table 3. The results and findings obtained for each load level is explained in the following subsections.

\section{1 $100 \%$ (Base Case) - 111\% Load Growth}

DSRs are used for flow control with N-1 contingency. Thus for the $100 \%$ load level all possible 35 single line contingencies are analysed. The 35 lines in the system were failed one at a time. Only 2 failed lines out of the 35 failed lines caused overloads. These overloads were all alleviated by the deployment of DSRs. Table 2 summarizes the findings of the 2 failed lines with overloads in the contingency analysis for the base case (Design \#1). It shows the number of DSRs deployed over each line, and the $\%$ of the total overload eliminated. The failure of Line 6-7 requires deployment of 
1650 DSRs on Line 5-6 to eliminate an overload of $13.76 \%$, and the failure of Line 5-8 requires deployment of 375 DSRs on Line 6-7 to eliminate an overload of 1.21\%.

Increasing the load to $110 \%$ and considering N-1 contingencies, overloads were observed for failure of 3 lines out of the 35 failed lines. The DSR design application was successful in alleviating these overloads. Results of the simulation of the unbalanced, 3-phase model for the $110 \%$ load are illustrated in Fig. 2-a. Note that the crosses (x) that appear on some of the lines in the following figures indicate independent loop markers and are used by the power flow algorithm [25].

For an increase in load to $111 \%$, overloads were observed for the failure of 4 lines out of the 35 lines. The DSR design application was not successful in alleviating all overloads caused by these contingencies. One Critical line was observed, Line 6-7. It caused overloads that could not be alleviated by DSRs. The findings of the Critical line with the new parallel construction for the $111 \%$ load level are presented in Design \#3 in Table 1.

As DSR deployment could not handle overloads caused by the failure of the Critical Line 6-7, a new similar $345 \mathrm{kV}$ parallel line was built. Results for the $111 \%$ load with the new line construction parallel to Line 6-7 is depicted in Fig. 2-b.

TABLE 1

\begin{tabular}{|c|c|c|c|c|}
\hline $\begin{array}{c}\text { Design } \\
\#\end{array}$ & $\begin{array}{c}\% \\
\text { System } \\
\text { Load }\end{array}$ & $\begin{array}{c}\text { Failed } \\
\text { Lines } \\
\text { Causing } \\
\text { Overload }\end{array}$ & $\begin{array}{c}\text { Critical } \\
\text { Lines }\end{array}$ & $\begin{array}{c}\text { Total } \\
\text { DSRs } \\
\text { Turned } \\
\text { On }\end{array}$ \\
\hline 1 & $100 \%$ & $6-7,5-8$ & & 2025 \\
\hline 2 & $110 \%$ & $\begin{array}{l}5-6,6-7, \\
5-8\end{array}$ & & 9525 \\
\hline 3 & $111 \%$ & - & $6-7$ & 0 \\
\hline 4 & $120 \%$ & $7-8,15-16$ & & 3075 \\
\hline 5 & $121 \%$ & $5-8,15-16$ & & 4200 \\
\hline 6 & $122 \%$ & $7-8$ & $15-16$ & 300 \\
\hline 7 & $130 \%$ & $2-3,7-8$ & & 1800 \\
\hline 8 & $135 \%$ & $\begin{array}{l}2-3,4-5 \\
7-8,6-11 \\
4-14,16- \\
19\end{array}$ & & 4500 \\
\hline 9 & $136 \%$ & $7-8$ & $2-3$ & 1050 \\
\hline 10 & $140 \%$ & $7-8,6-11$ & & 1575 \\
\hline
\end{tabular}


TABLE 2

DSR DEPLOYMENT RESULTS OF THE N-1 CONTINGENCY ANALYSIS FOR ALL LOAD LEVELS

\begin{tabular}{|c|c|c|c|c|c|}
\hline $\begin{array}{c}\text { Design } \\
\#\end{array}$ & $\begin{array}{c}\% \\
\text { System } \\
\text { Load }\end{array}$ & $\begin{array}{c}\text { Failed } \\
\text { Lines } \\
\text { Causing } \\
\text { Overload }\end{array}$ & $\begin{array}{c}\text { Lines } \\
\text { with } \\
\text { DSRs } \\
\text { Turned } \\
\text { On } \\
\end{array}$ & $\begin{array}{c}\text { No. of } \\
\text { DSRs } \\
\text { Turned } \\
\text { On }\end{array}$ & $\begin{array}{l}\text { \% Total } \\
\text { Overload } \\
\text { Removed }\end{array}$ \\
\hline \multirow[b]{2}{*}{1} & \multirow[b]{2}{*}{$100 \%$} & $6-7$ & $5-6$ & 1650 & 13.76 \\
\hline & & $5-8$ & $6-7$ & 375 & 1.21 \\
\hline \multirow{3}{*}{2} & \multirow{3}{*}{$110 \%$} & $5-6$ & $6-7$ & 1800 & 10.1 \\
\hline & & $6-7$ & $\begin{array}{l}5-6 \\
5-8 \\
\end{array}$ & $\begin{array}{l}2775 \\
3150 \\
\end{array}$ & $\begin{array}{c}26.55 \\
9.4 \\
\end{array}$ \\
\hline & & $5-8$ & $6-7$ & 3600 & 10.73 \\
\hline \multirow{2}{*}{4} & \multirow{2}{*}{$120 \%$} & $7-8$ & $5-6$ & 225 & 1.83 \\
\hline & & $15-16$ & $13-14$ & 2850 & 12.9 \\
\hline \multirow{2}{*}{5} & \multirow{2}{*}{$121 \%$} & $5-8$ & $5-6$ & 375 & 2.72 \\
\hline & & $15-16$ & $13-14$ & 3825 & 14.68 \\
\hline 6 & $122 \%$ & $7-8$ & $5-6$ & 300 & 2.37 \\
\hline \multirow{2}{*}{7} & \multirow[t]{2}{*}{$130 \%$} & $2-3$ & $\begin{array}{c}5-6 \\
13-14 \\
\end{array}$ & $\begin{array}{l}300 \\
600 \\
\end{array}$ & $\begin{array}{l}1.71 \\
2.68 \\
\end{array}$ \\
\hline & & $7-8$ & $5-6$ & 1200 & 9.58 \\
\hline \multirow{6}{*}{8} & \multirow{6}{*}{$135 \%$} & $2-3$ & $\begin{array}{c}5-6 \\
13-14 \\
\end{array}$ & $\begin{array}{l}1575 \\
2700 \\
\end{array}$ & $\begin{array}{c}9.77 \\
10.67 \\
\end{array}$ \\
\hline & & $4-5$ & $13-14$ & 150 & 0.86 \\
\hline & & $7-8$ & $5-6$ & 1800 & 14.39 \\
\hline & & 6-11 & $13-14$ & 375 & 2.05 \\
\hline & & 4-14 & $5-6$ & 225 & 2.46 \\
\hline & & 16-19 & $13-14$ & 375 & 2.5 \\
\hline 9 & $136 \%$ & $7-8$ & $5-6$ & 1050 & 8.74 \\
\hline \multirow{2}{*}{10} & \multirow{2}{*}{$140 \%$} & $7-8$ & $5-6$ & 1500 & 12.32 \\
\hline & & $6-11$ & $13-14$ & 75 & 0.36 \\
\hline
\end{tabular}

TABLE 3

\begin{tabular}{|c|c|c|c|c|c|}
\cline { 2 - 6 } & \multicolumn{5}{c|}{ MAXIMUM \% CHANGE IN IMPEDANCE FOR LINES WITH DSRS DEPLOYED } \\
\cline { 2 - 6 } & Line 5-6 & Line 6-7 & $\begin{array}{c}\text { Line } \\
\mathbf{1 3 - 1 4}\end{array}$ & Line 5-8 & Line 7-8 \\
\hline $\mathbf{1 1 0 \%}$ & 68.25 & 61.48 & 0 & 48.94 & 0 \\
\hline $\mathbf{1 2 1 \%}$ & 9.18 & 0 & 62.66 & 0 & 0 \\
\hline $\mathbf{1 3 5 \%}$ & 44.21 & 0 & 44.18 & 0 & 0 \\
\hline $\mathbf{1 4 0 \%}$ & 36.82 & 0 & 1.22 & 0 & 0 \\
\hline
\end{tabular}

Fig. 2-a shows how the deployment of DSRs over Line 5-6, Line 5-8, and Line 6-7 was capable of handling all overloads at the $110 \%$ load level. When load was further increased to $111 \%$, DSR deployment was not able to handle all overloads and Line 6-7 was observed as a critical line. 


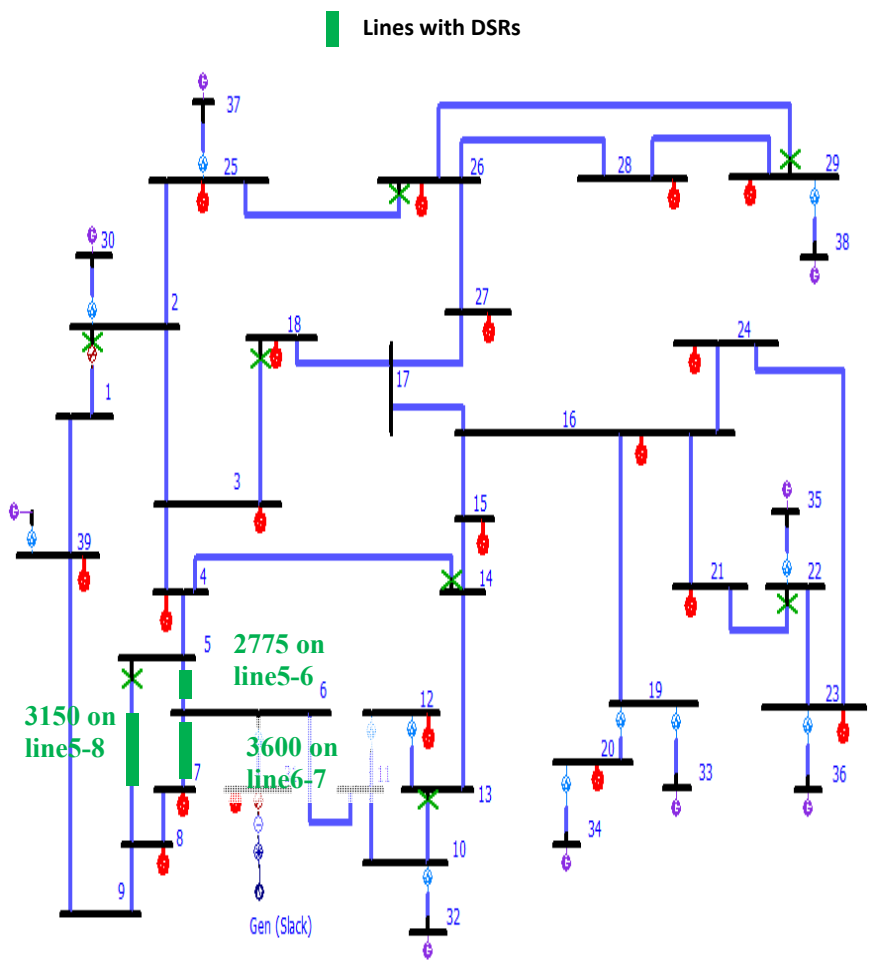

Fig. 2-a DSR design \#2 for $110 \%$ system load

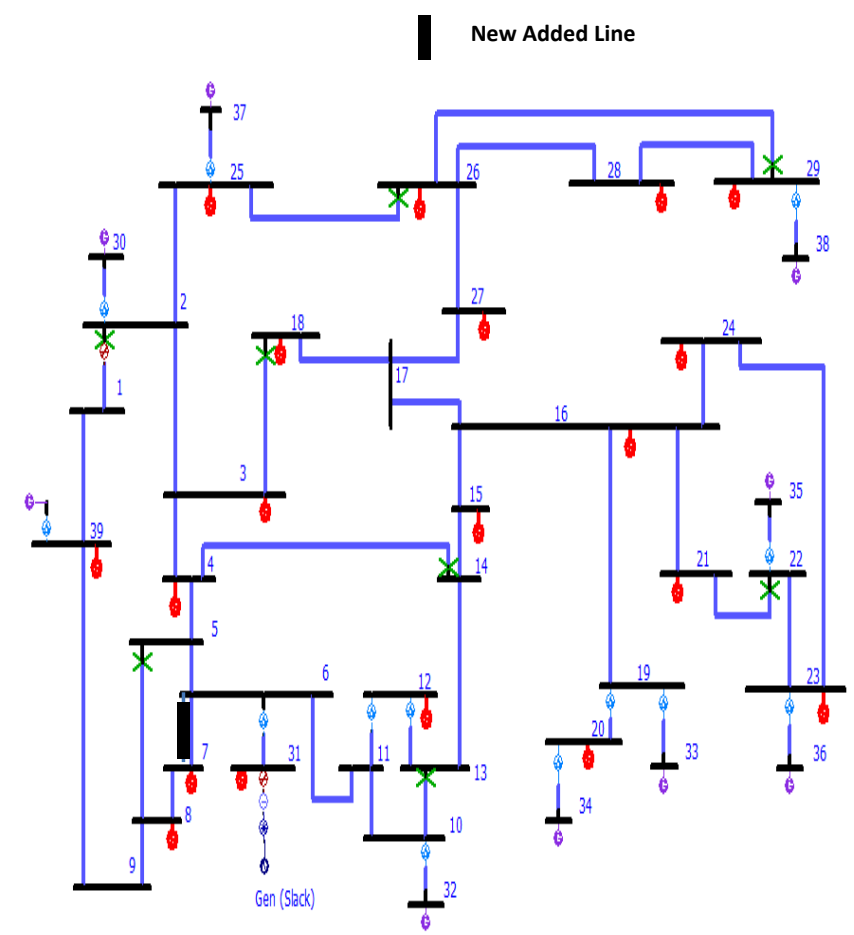

Fig. 2-b DSR design \#3 for $111 \%$ system load 
Fig. 2-b illustrates that with the new construction of Line 6-7 at the $111 \%$ load level, all N-1 contingencies could be handled and no DSR deployment was necessary.

\section{$4.2111 \%$ - 122\% Load Growth}

With the construction of a new $345 \mathrm{kV}$ line in parallel with Line 6-7 in Design \#3 at the 111\% load level, the load was further increased and DSR deployment succeeded in alleviating all overloads for $\mathrm{N}-1$ contingencies till a critical line, Line $15-16$, was observed at the $122 \%$ load level.

Tables 1 and 2 present the simulation results for the different system load levels up to the load growth of $122 \%$, where new line construction of a line parallel to a critical line, Line $15-16$, was implemented in Design \#6.

The results of Design \#6show how overloads at the $122 \%$ load level are alleviated when constructing a new line parallel to Line15-16 and deploying 300 DSR modules over Line 5-6.

\section{3 $122 \%-136 \%$ Load Growth}

At $122 \%$ load, the system has 2 new built lines that are in parallel with Line 6-7 and Line 15-16. Load was further increased with the DSR design managing to alleviate overloads caused by line outages until $135 \%$. At the $136 \%$ load level, Line $2-3$ was observed as a critical line. Thus, in Design \#9, shown in Tables 1 and 2, a new line was constructed parallel to Line 2-3. In Design \#9, while constructing a new line parallel to Line 2-3, 1050 DSRs were also deployed over Line 5-6 to ensure security under all N-1 contingencies at the $136 \%$ load level.

\subsection{6\% - 140\% Load Growth}

After a new line was constructed in parallel with Line 2-3 in Design \#9 at 136\% load, the system had 3 new lines. Load was further increased and all N-1 contingencies were handled by deployment of DSRs until a load level of $140 \%$ was reached. No more new line construction was required. Results for the $140 \%$ load level are presented in Tables 1 and 2.

Some observations obtained from the results shown in Tables 1, 2 and 3 are:

- The three critical lines identified at the $111 \%, 122 \%$, and $136 \%$ load levels represent weak points in the original system. 
- Lines whose outage cause overloads for several consecutive loading levels tend to turn into critical lines as the load increases. This is observed for the three critical lines of this study in Table 1.

- Adding DSRs for flow control can sometimes result in a high percentage change in impedance as shown in Table 3. This may cause voltage drops which require addition of more reactive controls.

For Design \#10, the voltages for lines with DSRs (Line 5-6 and Line 13-14), are reported in

Table 4 . The goal in this study was to keep the voltage drop within $\pm 10 \%$ of the nominal voltage.

The percentage of voltage imbalance is calculated using

$\frac{\text { maximum deviation from average voltage }}{\text { average voltage }} * 100 \%$

$\frac{\max \{|\mathrm{Vav}-\mathrm{VA}|,|\mathrm{Vav}-\mathrm{VB}|,|\mathrm{Vav}-\mathrm{VC}|\}}{\operatorname{Vav}} * 100 \%$

where $\mathrm{V}_{\mathrm{av}}$ is the average voltage, and $\mathrm{V}_{\mathrm{A}}, \mathrm{V}_{\mathrm{B}}$, and $\mathrm{V}_{\mathrm{C}}$ are the phase voltages. The voltage imbalance observed with DSRs deployed at the $140 \%$ load level is higher than that for the base case with no DSRs. The voltage imbalance obtained could be corrected by placing different numbers of DSRs on different phases.

TABLE 4

VOLTAGE OF LINES WITH \& WITHOUT DSRS FOR 100\% AND 140\% LOAD

\begin{tabular}{|c|c|c|c|c|c|c|}
\hline \multirow{2}{*}{$\begin{array}{c}\text { Load } \\
\text { Level \% }\end{array}$} & \multirow{2}{*}{$\begin{array}{c}\text { Lines with } \\
\text { DSRs }\end{array}$} & \multirow{2}{*}{ \# DSRs Deployed } & \multicolumn{3}{|c|}{ Voltage (p.u.) } & \multirow{2}{*}{ Imbalance \% } \\
\cline { 4 - 6 } & & & Phase A & Phase B & Phase C & \\
\hline \multirow{2}{*}{$100 \%$} & Line5-6 & - & 1.0127 & 1.031 & 1.0304 & 1.17 \\
\cline { 2 - 6 } & Line13-14 & - & 1.0255 & 1.0449 & 1.0451 & 1.25 \\
\hline \multirow{2}{*}{$140 \%$} & Line5-6 & 1500 & 0.9252 & 0.9743 & 0.9692 & 3.31 \\
\cline { 2 - 6 } & Line13-14 & 75 & 0.9391 & 0.9892 & 0.9849 & 3.33 \\
\hline
\end{tabular}

The highest $\%$ of overload removed is calculated at different $\%$ load levels and is depicted in Fig. 3. Fig. 3 also shows where new lines were built. The total load supplied and the numbers of DSRs deployed to remove the overload are presented in Fig. 4. 


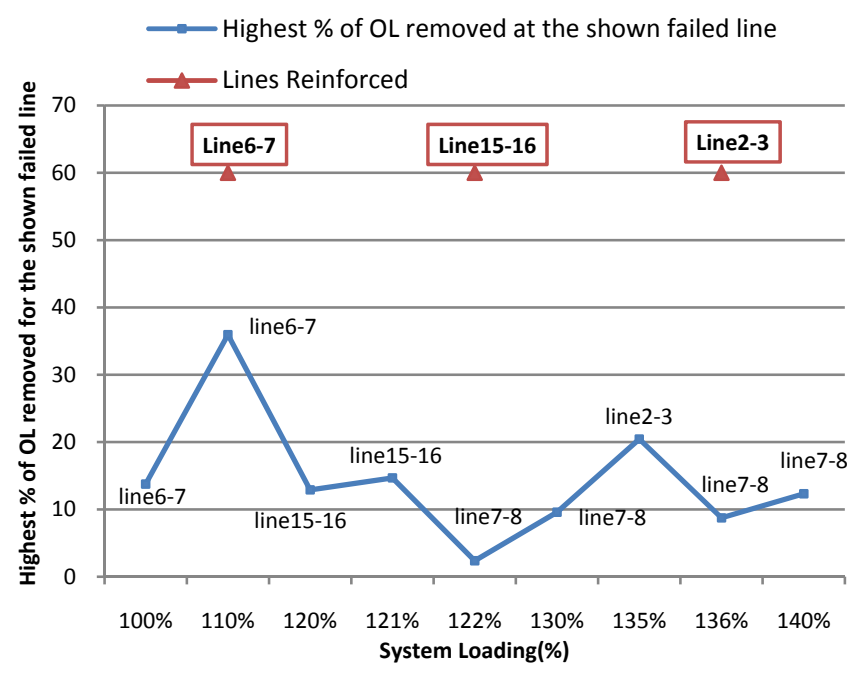

Fig. 3 Highest $\%$ of overload removed at different system load levels

It may be observed from Fig. 3 that for the same failed line the highest $\%$ of overload removed increases with the increase in system load level. Whenever the failed line was strengthened with a parallel one, the highest $\%$ of overload removed drops. It is also noted that the line whose outage has the highest $\%$ of overload removed tends to turn into a critical line as load level increases and is subsequently chosen to be strengthened with a similar parallel line.

\subsection{New Line Construction: Alternate Design}

As discussed in the previous section, the DSR design for the $140 \%$ load level provides for a significant load increase with a small number of DSRs where voltage drops at peak conditions are within the design criteria. This DSR design will shortly be compared with the conventional method of new line construction to reach the $140 \%$ load level. The study of using just new line construction to reach the $140 \%$ load level will be considered in this section. 


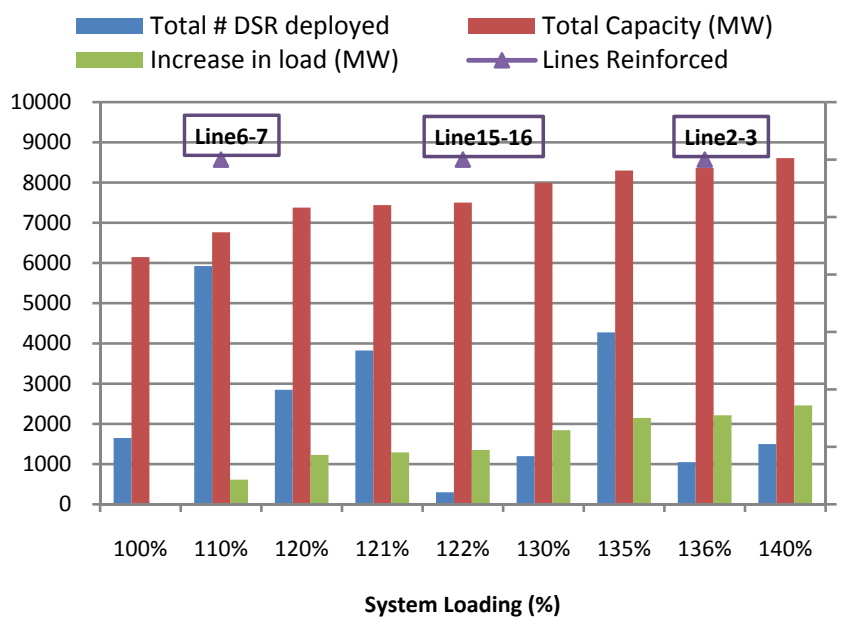

Fig. 4 DSRs deployed, increase in load, the total load supplied, and \% system loading at which line reinforcement occurred

The load is uniformly grown and if a line outage causes overloads, this line will be strengthened by constructing a new similar line parallel to it to alleviate the observed overloads. At the $100 \%$ base case load, Line 6-7 and Line 5-8 outages caused overloads. By building a new line parallel to Line 6-7 the overloads were alleviated. At the $120 \%$ load level Line $7-8$ and Line $15-16$ were strengthened with similar parallel lines to alleviate overloads. For further load increases Line 2-3 was strengthened at the $130 \%$ load level and Line 6-11 was strengthened at the $140 \%$ load level. Thus 5 lines were added to the system to reach the targeted $40 \%$ load increase.

In addition to the same 3 lines strengthened in the DSR Design \#10 for the 140\% load level, 2 more lines, which are Line 7-8 and Line 6-11, were strengthened, resulting in 50.15 miles of new transmission lines[27]. Table 5 shows the 5 lines added and their length, highlighting the 2 additional lines for the alternate design of just adding new lines with no DSR addition.

TABLE 5

NEW LINE CONSTRUCTION FOR N-1 CONTINGENCY FOR 140\% LOAD GROWTH HIGHLIGHTING NEW LINES ADDED

\begin{tabular}{|c|c|c|c|}
\hline $\begin{array}{c}\text { \% System } \\
\text { Load }\end{array}$ & Line Outages Causing Overload & New Lines Added to Remove Overloads & Length in Miles \\
\hline $100 \%$ & Line6-7, Line5-8 & Line6-7 & 28.79 \\
\hline $110 \%$ & - & - & $29.09,22.67$ \\
\hline $120 \%$ & Line15-16,Line7-8 & Line15-16, Line7-8 & 36.69 \\
\hline $130 \%$ & Line2-3 & Line2-3 & 27.48 \\
\hline $140 \%$ & Line6-11 & Line 6-11 & \\
\hline
\end{tabular}




\subsection{Multi-Area Control Design}

This section presents the simulation results of using DSRs to control the power flow of a real power system over tie lines connecting different power pool areas and control the power flow over the transmission lines within an area itself. An area (Area1) with 525 buses (52 load buses, 64 generator buses) and 302 transmission lines is simulated. This area connects to its neighbouring area (Area2) through 8 tie lines. The maximum load power that can be supplied to the loads in Area1 with the existing transmission facilities is $11.35 \mathrm{GW}$. A further increase in load results in overloading the lines within Area 1 and overloads on the 8 tie lines. The DSR modules are used to alleviate the overload and control the power flow over the transmission lines and tie lines. Case studies for increases in load are investigated, where the load increases range from $5 \%-24 \%$ load growth. Table 6 depicts the total number of DSRs deployed in Area1 and the power delivered over the tie lines for the different load growth percentages.

From Table 6 it can be seen that at the early load increase percentages, till about $15 \%$ load growth, fewer numbers of DSRs are required. For the $120 \%$ load level and above, large numbers of DSR modules are needed.

TABLE6 DSRS DEPLOYED AND POWER DELIVERED FOR DIFFERENT LOAD GROWTH PERCENTAGES IN AREA1

\begin{tabular}{|c|c|c|c|c|c|c|c|c|}
\hline \% System Loading & $105 \%$ & $110 \%$ & $115 \%$ & $120 \%$ & $121 \%$ & $122 \%$ & $123 \%$ & $124 \%$ \\
\hline \#DSR Deployed & 300 & 1200 & 3600 & 12000 & 15000 & 16500 & 19200 & 24600 \\
\hline Power delivered [GW] & 11.88 & 12.37 & 12.86 & 13.34 & 13.43 & 13.53 & 13.62 & 13.71 \\
\hline Load increase $[G W]$ & 0.53 & 1.02 & 1.51 & 1.99 & 2.08 & 2.18 & 2.27 & 2.36 \\
\hline
\end{tabular}

For an increase of $1.5 \mathrm{GW}$ (15\% load growth) in load, 3600 DSR modules are required. For an increase of $2 \mathrm{GW}$ (20\% load growth) in load, 12000 modules are required. Thus, for a $0.5 \mathrm{GW}$ increase in load from $15 \%$ load growth to $20 \%$ load growth, more than 3 times the number of DSRs are required than for the previous $1.5 \mathrm{GW}$ increase. This implies that DSRs may be more effective during early stages of load increase. Detailed results for the $15 \%$ load growth case are presented here. 
For a load growth of $15 \%$, two transmission lines and three tie-lines are overloaded. Appling the DSR control algorithm, a total of 3600 DSRs are deployed over the six lines to alleviate the overload and to shift the power flow to other more lightly loaded lines in the system. The power supplied after this deployment is $12.86 \mathrm{GW}$, resulting in an increase of $1.5 \mathrm{GW}$ in load being achieved using 3600 DSR modules. Table 7 shows the results for the six lines before and after DSR deployment.

It is worth noting that transmission line3 was not overloaded, but that the DSRs deployed over it caused the shift of power flow over other lightly loaded lines to help in alleviating overloads and to achieve a better utilization of the transmission lines in the system.

TABLE 7 DSR DEPLOYMENT RESULTS FOR THE LOAD GROWTH OF 15\% IN AREA1

\begin{tabular}{|c|c|c|c|c|c|}
\hline Line type & No. of DSRs deployed & Max Load \% w/o DSR & Max Load \% with DSR & Total MVA w/o DSR & Total MVA with DSR \\
\hline Tie line1 & 300 & 115.6 & 86.7 & 426.5 \\
\hline Tie line2 & 300 & 105.5 & 95.6 & 236.3 & 214 \\
\hline Tie line3 & 300 & 103.5 & 99.6 & 146.9 & 141.3 \\
\hline Trans. line1 & 1200 & 110.6 & 99.6 & 204.3 \\
\hline Trans. line2 & 900 & 104.69 & 99.2 & 225.2 \\
\hline
\end{tabular}

\section{Economic Worth of DSR Design vs. New Line Construction}

In this section, the economic worth of the DSR design, evaluated in terms of conventional new line construction, is performed. This economic evaluation will be performed for the $140 \%$ load level.

\subsection{DSR Design}

Table 8 shows the number of DSRs to be added and deployed over each line for each year to support a load growth to $140 \%$ in 40 years while handling N-1 contingency. To reach a load growth of $40 \%$ it is shown in Table 8 that along with the 3 new constructed lines (Line 6-7, Line 15-16 and Line 2-3), a total of 13350 DSRs were added to the system through the first 21 years. The 3 new $345 \mathrm{kV}$ lines added in parallel to critical lines resulted in approximately 95 miles of new 
transmission lines [27]. Table 2 presents the DSRs for each line for each load level design, and Table 8 presents the cumulative DSR design for $40 \%$ load growth while handling the N-1 contingency requirement. Fig. 5 depicts the number of DSRs added and the new lines constructed each year for the targeted $40 \%$ load growth.

TABLE 8

DSR MODULES DEPLOYED OVER EACH LINE PER YEAR

\begin{tabular}{|c|c|c|c|c|c|}
\hline $\begin{array}{c}\text { Lines with } \\
\text { DSRs }\end{array}$ & $\begin{array}{l}\text { Year } 0 \\
(100 \%)\end{array}$ & $\begin{array}{l}\text { Year } 10 \\
(110 \%)\end{array}$ & $\begin{array}{l}\text { Year } 20 \\
(120 \%)\end{array}$ & $\begin{array}{r}\text { Year } 21 \\
(121 \%)\end{array}$ & \\
\hline Line 5-6 & 1650 & 1125 & & & \\
\hline Line 6-7 & 375 & 3225 & & & \\
\hline Line 13-14 & & & 2850 & 975 & \\
\hline Line 5-8 & & 3150 & & & \\
\hline Total DSRs & 2025 & 7500 & 2850 & 975 & 13350 \\
\hline
\end{tabular}

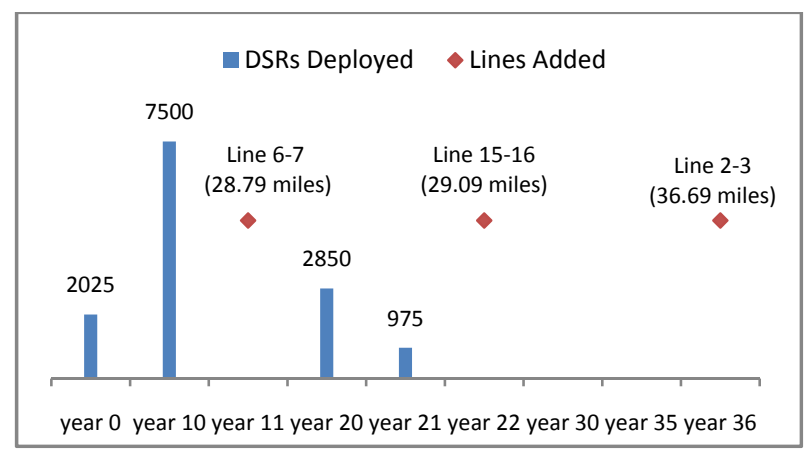

Fig. 5 DSRs and new lines added per year for $140 \%$ system load

\subsection{Alternative Design: New Line Construction}

In the new line construction design presented in section III-E, 5 new lines are added to reach the 140\% load level. In addition to the same 3 lines added in DSR Design \#10, Line 7-8 and Line 6-11 were constructed, resulting in the addition of about 51 miles of new transmission lines.

Table 9 shows the 5 lines added and their lengths, highlighting the 2 additional lines added for the new line construction alternate design study. Fig. 6 depicts the lines in miles built each year to support the $40 \%$ load growth in 40 years.

Fig. 6 shows the 5 lines added at years $0,20,30$ and 40, corresponding to the load levels $100 \%$, $120 \%, 130 \%$ and $140 \%$, as presented in Table 5 . 
From Fig. 5 and 6 it may be seen that the DSR design is delaying the construction of new lines for over 10 years.

TABLE 9

TOTAL LENGTH IN MILES FOR NEW LINES CONSTRUCTED

\begin{tabular}{|c|c|c|}
\hline 5 Lines added & Length (mile) & Total length(mile) \\
\hline Line2-3 & 36.69 & \\
\hline Line6-7 & 28.79 & \\
\hline Line15-16 & 29.09 & 94.57 \\
\hline Line 7-8 & 22.67 & \\
\hline Line6-11 & 27.48 & 50.15 \\
\hline & & 144.72 \\
\hline
\end{tabular}

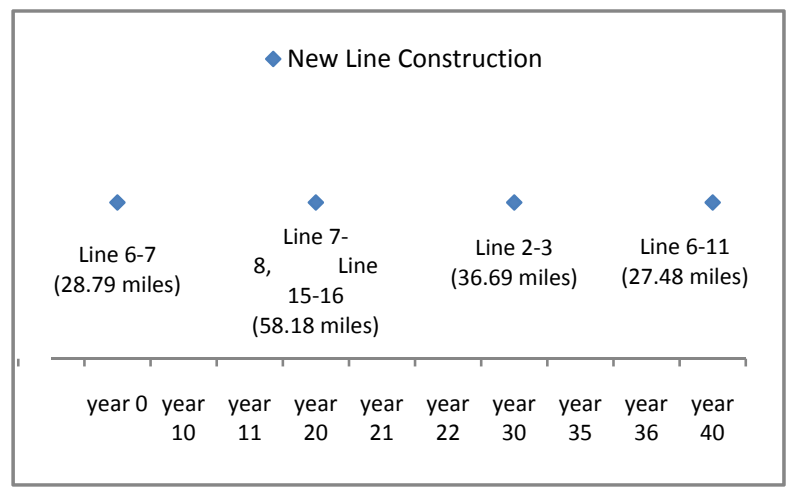

Fig. 6 New lines constructed per year for a 140\% system load with the New Line Construction Alternate Design

\subsection{DSR Worth Evaluation}

The cost of the new line construction design will be used to evaluate the economic value of the DSRs. The evaluation uses the present worth value, shown in (7), for each design presented in the previous 2 subsections. This calculation sets an upper limit on the worth of a DSR. The present worth value for the two designs are shown in (8) and (9).

$$
\text { Present Value }(P)=\frac{\text { Future Value }(F)}{(1+i)^{n}}
$$

\section{Present worth value for the DSR design =}

[Present value of DSRs deployed] + [Present value of lines added]

$$
\begin{aligned}
& =\left[2025 * \mathrm{C}_{\mathrm{DSR}}+7500 * \mathrm{C}_{\mathrm{DSR}} /(1+0.1)^{10}+2850 * \mathrm{C}_{\mathrm{DSR}} /(1+0.1)^{20}+975^{*} \mathrm{C}_{\mathrm{DSR}} /(1+0.1)^{21}\right. \\
& ]+\left[\left(28.79 * \mathrm{C}_{\mathrm{Line}}\right) /(1+0.1)^{11}+\left(29.09 * \mathrm{C}_{\mathrm{Line}}\right) / \quad(1+0.1)^{22}+\left(36.69 * \mathrm{C}_{\text {Line }}\right) /(1+0.1)^{36}\right]
\end{aligned}
$$


where $\mathrm{C}_{\mathrm{DSR}}$ is the cost of one DSR module, and $\mathrm{C}_{\mathrm{Line}}$ is the construction cost of the $345 \mathrm{kV}$ line per mile. An interest rate of $10 \%$ is assumed.

\section{Present worth value of the new line construction design $=$}

$\left(28.79 * \mathrm{C}_{\text {Line }}\right)+\left(58.18 * \mathrm{C}_{\text {Line }}\right) /(1+0.1)^{20}+\left(36.69 * \mathrm{C}_{\text {Line }}\right) /(1+0.1)^{30}+\left(27.48 * \mathrm{C}_{\text {Line }}\right) /(1+0.1)^{40}$

By equating (5.2) with (5.3) that has the cost of a DSR as an unknown, an upper limit on the cost of a DSR that will make it a better investment can be estimated, as shown in (10).

$$
\begin{aligned}
& {\left[2025 * \mathrm{C}_{\mathrm{DSR}}+7500 * \mathrm{C}_{\mathrm{DSR}} /(1+0.1)^{10}+2850 * \mathrm{C}_{\mathrm{DSR}} /(1+0.1)^{20}+975^{*} \mathrm{C}_{\mathrm{DSR}} /(1+0.1)^{21}\right]+\left[\left(28.79 * \mathrm{C}_{\text {Line }}\right) /\right.} \\
& \left.(1+0.1)^{11}+\left(29.09 * \mathrm{C}_{\text {Line }}\right) /(1+0.1)^{22}+\left(36.69 * \mathrm{C}_{\text {Line }}\right) /(1+0.1)^{36}\right] \\
& \quad= \\
& \left(28.79 * \mathrm{C}_{\text {Line }}\right)+\left(58.18 * \mathrm{C}_{\text {Line }}\right) /(1+0.1)^{20}+\left(36.69 * \mathrm{C}_{\text {Line }}\right) /(1+0.1)^{30}+\left(27.48 * \mathrm{C}_{\text {Line }}\right) /(1+0.1)^{40}
\end{aligned}
$$

Using a construction cost of a $345 \mathrm{kV}$ line $\mathrm{C}_{\mathrm{Line}}$ as $2.5 \mathrm{M} \$ /$ mile [28]-[30], the breakeven cost of a DSR is $C_{\mathrm{DSR}}=\$ 11,557 / \mathrm{DSR}$ module. Thus, if the cost of the DSR is less than $\$ 11,557$ per DSR it may be a better investment to deploy DSRs, especially since the DSRs provide control flexibility not available with the fixed construction. Additionally, the DSR design delays construction of lines, and thus, if load growth estimates are incorrect, it gives planners and operators some time to make better decisions about investments in new transmission lines. Moreover, DSRs can be moved around in the network if deployment decisions are not accurate.

\section{Conclusions}

This paper studied controlling power flow on unbalanced transmission lines using DSRs under N1 line contingencies. An unbalanced, 3-phase model of the physically modelled IEEE 39 bus system was used to simulate the placement of DSRs under load growth and N-1 contingency analysis while maintaining all system voltages within $+/-10 \%$ of nominal voltage. The authors assumed a projected load growth for the next 40 years of $1 \%$ per year. 
The DSR placement algorithm was used to try and find a DSR design that can be used to alleviate observed overloads. When DSRs were not able to handle all overloads, new line construction was implemented. Critical Lines were introduced and defined in this study as lines which when failed cause overloads that cannot be alleviated by DSR placement, and here construction of new lines is used to alleviate such overloads. At the $100 \%$ and $110 \%$ load levels DSRs were able to alleviate all overloads under N-1 contingencies. For the $111 \%, 122 \%$, and 136\% load levels, the system had weak points where DSRs could not relieve all the overloads observed under N-1 contingencies. These overloads were eliminated by constructing three new lines. However, this illustrates that DSRs can provide a solution to delaying the investment in infrastructure until a specific load growth percentage is reached.

DSR design to control the power flow of a real power system over tie lines connecting different power pool areas and to control the power flow over transmission lines within an area itself is investigated for different load growth values under N-1 tie line contingencies. DSRs were more effective at early stages of load increase, as during the early load growth stagesfewernumbers of DSRs were required to alleviate all overloads under N-1 contingencies.

An economic evaluation of DSRs for N-1 contingencies with load growth was presented. In the economic evaluation, the study of the system with just new lines construction versus deploying DSRs to supply a load level of $140 \%$ was investigated. The value of the DSRs when compared to new line construction came to 11,557 \$ per DSR.

DSRs can be cost effective in managing load increases from year to a year, and can delay making investments in new line construction until load expectations are proven to be true. Thus, a major value of DSRs is handling load growth in the short term is delaying larger investments. Furthermore, as illustrated in the example studies performed here, even when new line construction is performed, the past investments in DSRs continue to provide value. Moreover, DSRs can offer other value streams not considered in this paper, such as control for balancing unbalanced transmission system voltages. 


\section{Acknowledgement}

This research has been sponsored by the DOE ARPA-E GENI program, Smart Wire Grid, Electrical Distribution Design, and the Virginia Tech Middle East and North Africa (VT-MENA).

\section{References}

[1] M. S. Sarma, J. D. Glover and T. J. Overbye, Power System Analysis and Design, $5^{\text {th }}$ ed., SI, Global Engineering, 20082012.

[2] M.S.Alam, M.A.Razzak, M.N.Hasan, A.H.Chowdhury, "Transmission capacity enhancement of East-West Interconnectors using series-shunt compensation," 2012 7th International Conference on Electrical \& Computer Engineering (ICECE), pp.579,582, 2022 Dec. 2012. doi: 10.1109/ICECE.2012.6471616

[3] T.Krontiris, A.Wasserrab, G. Balzer, "Weather-based loading of overhead lines - Consideration of conductor's heat capacity," 2010 Proceedings of the International SymposiumModern Electric Power Systems (MEPS), pp.1,8, 20-22 Sept. 2010.

[4] S.C.Muller, U.Hager, C.Rehtanz, "A Multiagent System for Adaptive Power Flow Control in Electrical Transmission Systems," IEEE Transactions on Industrial Informatics, vol.10, no.4, pp.2290,2299, Nov. 2014. doi: 10.1109/TII.2014.2315499

[5] H.Rafiq, S.Shakeel, S.Nawaz, M.K.Bashir, Y.Saleem, M.Saleem, T.Izhar, "Control system design of UPFC for optimal power flow control," 2013 International Conference on Open Source Systems and Technologies (ICOSST) , pp.23,27, 16-18 Dec. 2013. doi: 10.1109/ICOSST.2013.6720600

[6] G.T.Das, S.T.Kalyani, "Control and performance of UPFC connected to a transmission line," IPEC 2007 InternationalPower Engineering Conference, 2007, pp.302,307, 3-6 Dec. 2007

[7] S.Omran, R.Broadwater,J.Hambrick, M.Dilek, "DSR design fundamentals: Power flow control," 2014 IEEEPES General Meeting | Conference \& Exposition, pp.1,5, 27-31 July 2014. doi: 10.1109/PESGM.2014.6939497

[8] I. Grant, F. Kreikebaum, J. Shultz, S. Omran and R.Broadwater, "Initial Field Trials of Distributed Series Reactors and Implications for Future Application," CIGRE US National Committee 2014 Grid of the Future Symposium, 2014

[9] D.Das, F.Kreikebaum, D.Divan, F.Lambert, "Reducing transmission investment to meet Renewable Portfolio Standards Using Smart Wires," 2010 IEEE PESTransmission and Distribution Conference and Exposition, pp.1,7, 19-22 April 2010. doi: 10.1109/TDC.2010.5484217

[10] D.M.Divan, W.E.Brumsickle, R.S.Schneider, B.Kranz, R.W.Gascoigne, D.T.Bradshaw, M.R. Ingram, I.S.Grant, "A Distributed Static Series Compensator System for Realizing Active Power Flow Control on Existing Power Lines," IEEE Transactions onPower Delivery, vol.22, no.1, pp.642,649, Jan. 2007. doi: 10.1109/TPWRD.2006.887103

[11] D.Divan, H.Johal, "Distributed FACTS - A New Concept for Realizing Grid Power Flow Control," IEEE $36^{\text {th }}$ Power Electronics Specialists Conference, 2005. PESC '05. pp.8,14, 16-16 June 2005.

[12] R.H.Chen, J.Gao,O.P. Malik, G.S.Hope, S.Y.Wang, N.D.Xiang, "Multi-contingency preprocessing for security assessment using physical concepts and CQR with classifications," IEEE Transactions onPower Systems, vol.8, no.3, pp.840,848, Aug 1993. doi: $10.1109 / 59.260920$

[13] N.Hadjsaid, M.Benahmed, J.Fandino, J.C.Sabonnadiere, G.Nerin, "Fast contingency screening for voltage-reactive considerations in security analysis," IEEE Transactions onPower Systems, vol.8, no.1, pp.144,151, Feb 1993. doi: 10.1109/59.221260 
[14] C.Subramani,S.S.Dash, M.Arun Bhaskar, M.Jagadeeshkumar, K.Sureshkumar, R.Parthipan, "Line outage contingency screening and ranking for voltage stability assessment," International Conference onPower Systems, 2009. ICPS '09. pp.1,5, 27-29 Dec. 2009. doi: 10.1109/ICPWS.2009.5442743

[15] A.Sudersan, M.Abdelrahman,G.Radman,"Contingency selection and static security enhancement in power systems using heuristics-based genetic algorithms," Proceedings of the Thirty-Sixth Southeastern Symposium on System Theory, 2004. pp.556,560, 2004. doi: 10.1109/SSST.2004.1295720

[16] S.Weerasooriya,M.A.El-Sharkawi, M.Damborg, R.J.Marks, "Towards static-security assessment of a large-scale power system using neural networks," IEE Proceedings CGeneration, Transmission and Distribution, vol.139, no.1, pp.64,70, Jan 1992.

[17] E.Vaahedi, C.Fuchs, W.Xu, Y.Mansour, H.Hamadanizadeh, G.K.Morison, "Voltage stability contingency screening and ranking," IEEE Transactions onPower Systems, vol.14, no.1, pp.256,265, Feb 1999. doi: 10.1109/59.744541

[18] S.Shivashankar, "Optimal location of TCSC in transmission lines using contingency severity index and performance index methods for single contingency using PSO," 2013 International Conference onPower, Energy and Control (ICPEC), pp.135,138, 6-8 Feb. 2013. doi: 10.1109/ICPEC.2013.6527638

[19] L.Jebaraj, N.Muralikrishnan, Rajan, C.Christober Asir, "DE algorithm based comparison between two different combinations of FACTS devices under single line outage contingency condition," 2013 7th International Conference on Intelligent Systems and Control (ISCO) , pp.158,165, 4-5 Jan. 2013. doi: 10.1109/ISCO.2013.6481141

[20] H.Monsef, M.Jaefari, "Transmission cost allocation based on use of reliability margin under contingency conditions," IETGeneration, Transmission \& Distribution, vol.3, no.6, pp.574,585, June 2009. doi: 10.1049/iet-gtd.2007.0352

[21] H.I.Shaheen, G.I.Rashed, S.J.Cheng, "Optimal location and parameters setting of UPFC based on GA and PSO for enhancing power system security under single contingencies," 2008 IEEEPower and Energy Society General Meeting - Conversion and Delivery of Electrical Energy in the 21st Century, pp.1,8, 20-24 July 2008. doi: 10.1109/PES.2008.4596594

[22] K.S.Sundar, H.M.Ravikumar, "Enhancement of Power System Performance using TCSC," Joint International Conference onPower System Technology and IEEE Power India Conference, 2008. POWERCON 2008. pp.1,7, 12-15 Oct. 2008. doi: 10.1109/ICPST.2008.4745253

[23] M.Ja'fari, S.Afsharnia, "Voltage Stability Enhancement in Contingency Conditions Using Shunt FACTS Devices," EUROCON, 2007. The International Conference on "Computer as a Tool" , pp.1660,1665, 9-12 Sept. 2007. doi: 10.1109/EURCON.2007.4400445

[24] Sung-Hwan Song; Jung-Uk Lim; Seung-Wan Jung; Seung-Il Moon, "Preventive and corrective operation of FACTS devices to cope with a single line-faulted contingency," IEEEPower Engineering Society General Meeting, 2004. pp.837,842 Vol.1, 6-10 June 2004. doi: 10.1109/PES.2004.1372937

[25] M.Dilek, F.de Leon, R.Broadwater, S.Lee, "A Robust Multiphase Power Flow for General Distribution Networks," IEEE Transactions onPower Systems, vol.25, no.2, pp.760,768, May 2010. doi: 10.1109/TPWRS.2009.2036791

[26] R.Broadwater, P.Dolloff, T.Herdman, R.Karamikhova, A. Sargent "Minimum Loss Optimization in Distribution Systems: Discrete Ascent Optimal Programming,”, Electrical Power System Research Journal, vol. 36, no. 2, pp. 113-121, 1996.

[27] S. Omran, R. Broadwater, J. Hambrick, M. Dilek, C.Thomas, and F. Kreikebaum, "Load Growth and Power Flow Control with DSRs in Unbalanced Transmission Networks", International Journal of Electrical Power and Energy Systems, submitted May 2015 
[28] AEP (2008). American Electric Power - Transmission Facts. http://www.slideshare.net/ashishkc007/transmission-facts (accessed May 2015)

[29] "Transmission and Substation Capital Costs," Western Electricity Coordinating Council, Aug.2012

[30] A. Silverstein, "TRANSMISSION101 - Transmission Capital Cost by Voltage," NCEP Transmission Technologies Workshop, April, 2011. http://www.naruc.org/grants/Documents/Silverstein\%20NCEP\%20T-101\%200420111.pdf (accessed May 2015) 